\title{
A DISPUTA POLÍTICO-IDEOLÓGICA ENTRE A REFORMA AGRÁRIA REDISTRIBUTIVA E O MODELO DE REFORMA AGRÁRIA DE MERCADO DO BANCO MUNDIAL (1994-2005)
}

\author{
João Márcio Mendes Pereira*
}

Resumo: O trabalho analisa a disputa político-ideológica entre o modelo de reforma agrária de mercado (MRAM) do Banco Mundial (BM) e a reforma agrária redistributiva. Argumenta-se que o cerne dessa disputa reside no fato de que esse modelo foi criado para substituir o papel desapropriatório e redistributivo do Estado. Mostra-se que, em todos os países onde foi implementado (África do Sul, Colômbia, Guatemala e Brasil), as supostas vantagens atribuídas ao MRAM sobre a reforma agrária não se materializaram.

Palavras-chave: Estado, Banco Mundial, reforma agrária, reforma agrária de mercado.

O presente artigo analisa a disputa político-ideológica entre o modelo de reforma agrária de mercado (MRAM) do Banco Mundial (BM) e aquilo que se convencionou chamar de reforma agrária redistributiva. Esse embate já dura onze anos, desde o início, em 1994, de programas orientados pelo MRAM na África do Sul e na Colômbia. No Brasil, tais programas existem desde 1997, tendo sido criados pelo governo Cardoso e seqüenciados pelo governo Lula. Todos eles fazem parte da ofensiva do BM direcionada à criação de políticas agrárias ajustadas aos parâmetros neoliberais.

Para legitimar o MRAM, o BM efetuou duas operações simultâneas: de um lado, procedeu a uma crítica radical ao que ele

* Doutorando em História pela Universidade Federal Fluminense, mestre em Desenvolvimento, Agricultura e Sociedade pelo CPDA-UFRRJ. Contato eletrônico: joao_marcio1917@yahoo.com.br

Recebido em 21 jul. 2005; aprovado em 22 nov. 2005. 
mesmo denominou de reforma agrária "conduzida pelo Estado", baseada no instrumento da desapropriação; de outro, trabalhou para que o MRAM fosse aceito política e conceitualmente como uma modalidade específica de reforma agrária redistributiva. Com esse duplo movimento, o BM continuou a reconhecer a necessidade de uma reforma agrária para desconcentrar a propriedade da terra em sociedades altamente desiguais, mas passou a negar a atualidade da ação desapropriacionista e redistributiva do Estado. O MRAM, metamorfoseado em reforma agrária redistributiva, foi ungido no contexto ultra-liberal pós-Guerra Fria como o modelo de ação estatal adequado aos países do Sul marcados por grave problema agrário.

O texto discute a lógica desse processo. Assim, no item 1, sintetizam-se os pilares do MRAM, que são a crítica do BM à reforma agrária desapropriacionista, as supostas vantagens do novo modelo e o deslizamento semântico entre o MRAM e a reforma agrária redistributiva. No item 2, distingue-se entre a versão original do MRAM, jamais implementada, e aquela que, de fato, se materializou, sob formatos específicos, na África do Sul, Guatemala, Colômbia e Brasil. No item 3, encontra-se uma crítica ao MRAM, cujo objetivo é mostrar que: a) o que está em disputa hoje é a legitimidade do papel redistributivo do Estado; b) o MRAM não apenas não deve ser confundido com qualquer modalidade de reforma agrária redistributiva, como é antagônico a ela; c) os resultados do MRAM na África do Sul, Guatemala, Colômbia e Brasil revelam que as suas supostas vantagens sobre o modelo desapropriacionista não se confirmaram. Por fim, no item 4, analisam-se as perspectivas do MRAM enquanto proposta política no cenário internacional contemporâneo.

\section{Pilares do modelo de reforma agrária de mercado}

\subsection{A crítica à reforma agrária "conduzida pelo Estado"}

O pressuposto do MRAM é o da falência histórica do que os economistas do BM denominaram de reforma agrária "conduzida pelo Estado", modelo "desapropriacionista" ou, simplesmente, modelo 
"tradicional" de reforma agrária. Ou seja, o MRAM foi criado para substituir algo que, segundo o discurso do BM, deixou de ser viável ou mesmo desejável na atual fase do capitalismo.

Em linhas gerais, ${ }^{1}$ o chamado modelo "tradicional" de reforma agrária teria se tornado inviável e indesejável na atualidade porque:

a) é politicamente conflituoso e as condições para a sua execução não são replicáveis em condições democráticas "normais", uma vez que contém uma dimensão "confiscatória" (quando a indenização aos proprietários inexiste ou é fixada abaixo dos preços de mercado) contra a qual se insurgiriam os grandes proprietários de terra;

b) é insustentável financeiramente, por compensar os antigos proprietários a preços de mercado, os quais são distorcidos por políticas econômicas e setoriais que elevam o preço da terra acima da rentabilidade gerada pela atividade agrícola;

c) é orientado para "substituir os mercados", e não para dinamizá-los, resultando num complexo de restrições legais que teriam solapado o funcionamento dos mercados de arrendamento e de compra e venda de terras, dificultado o acesso à terra por potenciais demandantes mais eficientes e alimentado burocracias centrais encapsuladas em busca de sua auto-reprodução e, freqüentemente, corruptas;

d) por ser baseado na desapropriação, carrega um componente coercitivo que enseja contestações judiciais que não apenas elevam a indenização dos antigos proprietários acima dos preços praticados no mercado, mas também retardam o processo de assentamento, prejudicando os potenciais beneficiários;

e) na prática constitui uma doação do Estado, pois os trabalhadores assentados não pagam pela terra recebida, o que alimenta o endividamento público;

f) é pautado pela lógica do conflito, uma vez que só são desapropriadas propriedades rurais objeto de ocupações de terra ou tensões sociais; 
g) quando isto não ocorre, funciona como um modelo dirigido pela oferta, cabendo ao Estado selecionar a terra ou os beneficiários independentemente da demanda real; historicamente, esse processo de seleção não foi comandado por critérios técnicos ou de necessidade, mas sim por ingerências políticas, o que gerou ineficiência econômica, baixa competitividade e não necessariamente focalizou a parcela mais pobre do campesinato;

h) não resolveu o problema da falta de acesso à terra para um amplo contingente de trabalhadores rurais, situação que estaria na origem de ocupações de terra, conflitos agrários e violência rural;

i) não criou condições para a competitividade econômica do setor reformado, ainda mais se se tem em vista o processo atual de liberalização dos mercados agrícolas e modernização tecnológica;

j) é um modelo centralizado, estatista e burocrático, que desestimula a participação social, a transparência e o "empoderamento" dos beneficiários, e não cria as condições adequadas para as necessárias sinergias entre os setores público e privado; também não permite a fluidez dos mercados e das informações necessária à orientação dos agentes econômicos, nem oferece condições para captar a heterogeneidade socioeconômica e cultural do universo rural;

1) é um modelo dirigido pela oferta, na medida em que cabe ao Estado selecionar a terra ou os beneficiários independentemente da demanda real; historicamente, esse processo de seleção não foi comandado por critérios técnicos ou de necessidade, mas sim por ingerências políticas, o que gerou ineficiência econômica, baixa competitividade e não necessariamente focalizou a parcela mais pobre do campesinato; 
m) de modo geral, restringiu-se tão-somente à distribuição de terra, dando pouca ênfase ao desenvolvimento produtivo dos assentados;

n) não oferece "opções de saída" para os produtores agrícolas ineficientes, seja porque sua implementação foi acompanhada por medidas restritivas ao funcionamento dos mercados de arrendamento e compra e venda, seja porque não incorporou a questão do trabalho não-agrícola;

o) integra o rol de políticas típicas do modelo de desenvolvimento por substituição de importações, que penaliza os pequenos agricultores e o setor agrícola, protege segmentos economicamente ineficientes e não responde aos imperativos da liberalização comercial.

Para superar os problemas atribuídos à chamada "reforma agrária conduzida pelo Estado", baseada na desapropriação de propriedades improdutivas que não cumprem a sua função social, o $\mathrm{BM}$ criou o modelo de reforma agrária de mercado.

\subsection{As supostas vantagens do modelo de reforma agrária de mercado}

O novo modelo consiste numa ação estatal que combina transação patrimonial privada e política distributiva (Borras, 2001). Transação patrimonial por tratar-se de um financiamento concedido para a compra e venda voluntária entre agentes privados - ou seja, uma típica operação mercantil -, e pelo fato de que os proprietários são pagos em dinheiro e a preço de mercado, enquanto os compradores assumem integralmente os custos da aquisição da terra e os custos de transação. Política distributiva porque há transferência de recursos a fundo perdido, em proporção variável conforme o caso, para investimentos em infra-estrutura e produção agrícola. Em outras palavras, trata-se de uma mera relação de compra e venda de terras entre agentes privados financiada pelo Estado, que fornece um subsídio maior ou menor conforme o caso. 
De acordo com os seus proponentes, a oportunidade histórica para implementá-lo resulta da queda do preço da terra e da redução dos privilégios estatais conferidos a grandes proprietários por força da adoção de reformas macroeconômicas e políticas de ajuste estrutural. Assim, seria possível realizar uma "reforma agrária menos nociva ao funcionamento dos mercados" (Deininger \& Binswanger, 1999, p. 267). Esta é a premissa básica do MRAM, que lhe serve também de justificativa: a criação de um novo ambiente econômico - "aberto" e "orientado para fora" - por força das políticas neoliberais, no qual diminuem as "distorções" que antes elevavam o preço da terra acima da rentabilidade agrícola e restringiam a sua oferta no mercado.

Segundo os teóricos do BM, existem duas características fundamentais que diferenciam completamente o MRAM do chamado "modelo desapropriacionista". A primeira seria a de que o MRAM tem como objetivo estimular ao máximo a compra e venda de propriedades rurais, enquanto o outro as prejudicaria por limitar a mercantilização da terra entre os beneficiários da reforma agrária e entre estes e os agentes econômicos interessados em adquirir imóveis rurais para a produção agrícola (Deininger \& Binswanger, 1999, p. 267). A segunda característica seria a de que o MRAM tem um caráter "negociado" e "voluntário", ao passo que o outro seria "coercitivo", posto que baseado num ato discricionário do Estado, a desapropriação (Burki \& Perry, 1997, p. 95).

Resumidamente, ${ }^{2}$ o BM afirma que o MRAM é melhor do que a tal reforma agrária "conduzida pelo Estado" porque:

a) é mais barato, em função da terra ser adquirida através da barganha mercantil entre compradores e vendedores voluntários, sobre a qual não cabem recursos judiciais que elevam a quantia paga ao proprietário;

b) em função do seu caráter voluntário, descentralizado e "dirigido pela demanda", favorece a participação e a autonomia dos beneficiários, estimula ações criativas para 
a superação de dificuldades e corresponde melhor às necessidades da realidade local;

c) não entra em conflito com os proprietários de terra, um vez que se baseia na livre transação mercantil entre compradores e vendedores interessados;

d) estimula a cooperação, na medida em que a aquisição de terras e o financiamento se dá via associações comunitárias;

e) incentiva o desenvolvimento produtivo dos agricultores, seja porque fornece recursos a fundo perdido para tal fim, seja porque estimula o associativismo e a busca de soluções cooperativas;

f) estimula a criação e/ou dinamização dos mercados de terra, requisito básico para a melhoria da eficiência econômica;

g) contribui para a formalização dos direitos de propriedade, na medida em que, por um lado, só transaciona imóveis titulados e, por outro, dá origem a novos segmentos de proprietários;

h) estimula o desenvolvimento dos mercados financeiros rurais, na medida em que os novos proprietários, com títulos seguros, passam a transacionar nos mercados de terra e a demandar crédito;

i) oferece opções de saída para os agricultores menos eficientes, permitindo que outros (mais eficientes) possam ter acesso à terra;

j) permite a realização simultânea de atividades agrícolas e não-agrícolas, uma vez que são os próprios agricultores que decidem que tipo de investimento e atividade querem desenvolver;

1) é uma relação contratual de compra e venda, cujo descumprimento implica a perda de terra; 
m) é mais coerente com os imperativos da liberalização das economias nacionais, a qual pressupõe a fluidez das relações mercantis em todos os setores.

O Quadro 1 sintetiza o discurso do BM em favor do MRAM e contra o modelo "tradicional" de reforma agrária.

\section{Quadro 1 - Síntese da formulação do Banco Mundial a favor do MRAM}

\begin{tabular}{|c|c|c|}
\hline Variáveis de comparação & Modelo desapropriacionista & $\begin{array}{c}\text { Modelo de reforma agrária de mercado } \\
\text { (MRAM) }\end{array}$ \\
\hline $\begin{array}{l}\text { Método de aquisição de } \\
\text { terras e de indenização } \\
\text { aos antigos proprietários }\end{array}$ & $\begin{array}{c}\text { Coercitivo; baseado na desapropriação; } \\
\text { pagamento com títulos públicos, que podem } \\
\text { ser abaixo, na média ou acima dos preços de } \\
\text { mercado, de acordo com a correlação de forças } \\
\text { políticas }\end{array}$ & $\begin{array}{l}\text { Totalmente voluntário; pagamento em dinheiro } \\
\text { a preços de mercado }\end{array}$ \\
\hline Forma de execução & $\begin{array}{l}\text { Centralizada e dirigida pela burocracia estatal; } \\
\text { baixo grau de eficiência, participação, } \\
\text { transparência e responsabilização }\end{array}$ & $\begin{array}{c}\text { Descentralizada e altamente participativa; alto } \\
\text { grau de eficiência, transparência e } \\
\text { responsabilização }\end{array}$ \\
\hline $\begin{array}{l}\text { Identificação e seleção } \\
\text { dos beneficiários }\end{array}$ & $\begin{array}{c}\text { Controladas exclusivamente pelo Estado, } \\
\text { sujeitas a pressões políticas, corrupção e erros } \\
\text { administrativos que comprometem a eficiência } \\
\text { agrícola posterior }\end{array}$ & $\begin{array}{c}\text { Auto-seleção, o que garante que sejam } \\
\text { contemplados os mais eficientes e aptos para a } \\
\text { atividade agrícola }\end{array}$ \\
\hline Natureza e ritmo & $\begin{array}{c}\text { Política e legalmente conflitivo, em razão de } \\
\text { contestações judiciais, do lobby e, conforme o } \\
\text { caso, da resistência aberta dos proprietários; } \\
\text { burocrático e lento }\end{array}$ & Não conflitivo; pouco burocrático e rápido \\
\hline $\begin{array}{l}\text { Ambiente econômico onde } \\
\text { ocorre e orientação de } \\
\text { desenvolvimento a que se } \\
\text { vincula }\end{array}$ & $\begin{array}{c}\text { Orientado para dentro; protecionista; políticas } \\
\text { macroeconômicas enviesadas contra a } \\
\text { agricultura; predomínio do modelo de } \\
\text { substituição de importações }\end{array}$ & $\begin{array}{c}\text { Orientado para fora; não-protecionista; } \\
\text { políticas macroeconômicas neutras ou em } \\
\text { favor da agricultura; predomínio das políticas } \\
\text { liberais e das reformas estruturais de segunda } \\
\text { geração }\end{array}$ \\
\hline $\begin{array}{l}\text { Tipo de desenvolvimento } \\
\text { produtivo engendrado e } \\
\text { modalidades de assistência } \\
\text { técnica e crédito }\end{array}$ & \begin{tabular}{|c|} 
Desenvolvimento produtivo demorado, incerto \\
e precário; planejamento da produção posterior \\
à aquisição da terra; serviços de assistência \\
técnica estatais, centralizados, irregulares, \\
altamente precários e/ou ineficientes; baixa \\
oferta de crédito e poucos investimentos \\
\end{tabular} & $\begin{array}{c}\text { Desenvolvimento produtivo rápido, certo e } \\
\text { dinâmico; planejamento da produção antes da } \\
\text { aquisição da terra; serviços de assistência } \\
\text { técnica privados, descentralizados e altamente } \\
\text { eficientes; oferta ascendente de crédito e } \\
\text { investimentos }\end{array}$ \\
\hline $\begin{array}{l}\text { Opções de saída para os } \\
\text { ineficientes e incorporação } \\
\text { de atividades não-agrícolas }\end{array}$ & Sem previsão & Sistemáticas e abrangentes \\
\hline $\begin{array}{l}\text { Pagamento da terra } \\
\text { pelos beneficiários }\end{array}$ & $\begin{array}{l}\text { Sem previsão, devido à natureza política } \\
\text { do modelo; configura uma doação do Estado }\end{array}$ & $\begin{array}{l}\text { Previsto, devido à natureza contratual do } \\
\text { modelo; configura uma operação de mercado } \\
\text { financiada pelo Estado, na qual os } \\
\text { beneficiários assumem integralmente o custo } \\
\text { da aquisição da terra }\end{array}$ \\
\hline $\begin{array}{l}\text { Concessão de crédito para } \\
\text { produção agrícola }\end{array}$ & $\begin{array}{c}\text { Insuficiente; subsídios não-focalizados, } \\
\text { normalmente capturados por grandes e médios } \\
\text { proprietários; endividamento dos mais pobres }\end{array}$ & $\begin{array}{l}\text { Suficiente; concessão de recursos a fundo } \\
\text { perdido de maneira focalizada }\end{array}$ \\
\hline $\begin{array}{l}\text { Custo da reforma } \\
\text { e preço da terra }\end{array}$ & Elevados & Baixos \\
\hline $\begin{array}{c}\text { Participação } \\
\text { do setor privado }\end{array}$ & $\begin{array}{l}\text { Nenhuma, ou muito periférica, } \\
\text { reflexo do caráter estatista do modelo }\end{array}$ & $\begin{array}{c}\text { Prevista em várias áreas e } \\
\text { altamente estimulada pelo modelo }\end{array}$ \\
\hline $\begin{array}{c}\text { Tipo de relação com os } \\
\text { mercados de terra }\end{array}$ & Substituição & Estímulo \\
\hline $\begin{array}{c}\text { Articulação com estratégias } \\
\text { de desenvolvimento rural e } \\
\text { alívio da pobreza }\end{array}$ & Não articulado & Articulado \\
\hline Papel do Estado & $\begin{array}{c}\text { Desapropriar terras que não cumprem com a } \\
\text { sua função social, definida na legislação } \\
\text { vigente }\end{array}$ & $\begin{array}{l}\text { Fornecer um empréstimo para compra de } \\
\text { terras entre agentes privados, acrescido de } \\
\text { recursos a fundo perdido para investimento } \\
\text { produtivo }\end{array}$ \\
\hline
\end{tabular}




\subsection{O “deslizamento semântico" operado pelo Banco Mundial}

Os teóricos do BM reconhecem que é preciso realizar reformas agrárias redistributivas em sociedades marcadas por alto grau de concentração da propriedade da terra, de modo a melhorar a eficiência econômica e contribuir para a eqüidade social. Porém, o BM chama de "reforma agrária redistributiva" o que, na verdade, é o seu próprio modelo de reforma agrária de mercado. Os exemplos repetem-se ad nauseam. Eis apenas um:

O Banco irá ajudar programas de reforma agrária redistributiva em países com uma distribuição desigual de terras. O Banco ajudou a África do Sul no período 1992-1994 a desenvolver um programa de reforma agrária redistributiva, baseado em transações negociadas ou voluntárias entre compradores e vendedores, ao mesmo tempo em que subsidiava os pobres sem terra, a fim de lhes permitir adquirir terras. Essa abordagem, chamada de reforma agrária "negociada" ou "assistida pelo mercado", também está sendo desenvolvida na Colômbia, Brasil e Guatemala (...) com a assistência do Banco (Banco Mundial, 1997, p. 85, grifos meus).

Fica claro, pelo exposto, que se trata de uma tentativa de "transubstanciação" prática pelos teóricos do BM.

\section{Versões do modelo de reforma agrária de mercado}

É importante diferenciar as duas versões que estão na base da construção do MRAM como proposta política.

A primeira versão foi elaborada ainda na primeira metade dos anos 1990 em favor da aplicação do MRAM à realidade sul-africana (Van Zyl, Kirsten \& Binswanger, 1995; Aiyar, Parker \& Van Zyl, 1995, 1995a; Christiansen \& Van Den Brink, 1994). Segundo essa abordagem, naquele momento (1994-1995) a África do Sul não estava apenas saindo do apartheid e realizando as primeiras eleições democráticas de sua história, mas também enfrentando uma grave crise da agricultura nacional, expressa pelo endividamento de parte dos grandes produtores agrícolas e pela explosão de uma demanda 
social por terra reprimida durante décadas, situação que estaria sendo agravada pelos efeitos da liberalização comercial e das reformas macroeconômicas. Naquele contexto, segundo o Banco Mundial, haveria a oportunidade e a necessidade de se realizar transformações significativas na agricultura do país. O MRAM, então, foi pensado como instrumento principal para administrar a crise de endividamento de um segmento significativo do setor agropecuário capitalista e, ao mesmo tempo, atender à demanda social por terra.

Segundo essa proposição, a oportunidade para o MRAM estaria colocada na medida em que a distância entre o preço da terra e sua rentabilidade agrícola estivesse diminuindo desde 1984, devido às políticas de ajuste estrutural que vinham promovendo a redução da inflação e a retirada de alguns privilégios concedidos à grande agricultura comercial (Van Schalkwyk \& Van Zyl, 1995, p. 204; Christiansen \& Van Den Brink, 1994, p. 154-156). Em tais circunstâncias, ao criar um mercado de terras, a implementação do MRAM poderia ajudar a resolver a crise de endividamento do setor comercial (grãos e pecuária), aliviar problemas sociais e econômicos gerados pela liberalização e gerar milhares de empregos no meio rural (Binswanger \& Van Zyl, 1995, p. 254).

De acordo com os teóricos do BM, a realização do MRAM só seria possível se o governo sul-africano administrasse a crise de endividamento do setor comercial de maneira seletiva, evitando operações de "socorro geral" (blanket debt relief) que beneficiassem, indiscriminadamente, todos os segmentos. O esquema seria o seguinte:

a) o setor comercial "consolidado" seguiria incólume a mudanças ou a qualquer medida de assistência financeira, uma vez que já estaria "ajustado" à dinâmica da liberalização econômica;

b) o setor comercial considerado "viável" sob as novas condições macroeconômicas, porém altamente endividado, poderia receber assistência financeira, desde que condicionada à sua reestruturação produtiva; uma parte dos 
ativos fundiários sob seu controle seriam ofertados no mercado, e ficariam a cargo do setor bancário tanto a decisão sobre quais produtores receberiam assistência financeira, como a revisão das dívidas desse segmento;

c) o setor comercial considerado "inviável" sob as novas condições deixaria o setor agropecuário mediante "bônus de saída" (por exemplo, empréstimos subsidiados para abertura de novos negócios) e ofertaria integralmente as terras sob sua propriedade;

d) o setor bancário poderia auxiliar no aumento da oferta de terras, conforme executasse as dívidas dos segmentos "inviáveis" e participasse do saneamento financeiro dos segmentos "viáveis" em reestruturação;

e) o Estado poderia incrementar a oferta de terras vendendo propriedades públicas;

f) pelo lado da demanda, um mercado de terras seria criado pela provisão de recursos (empréstimos e doações) aos agricultores beneficiados pelo MRAM; inicialmente, o crédito para a compra da terra e os recursos a fundo perdido para o desenvolvimento produtivo viriam do governo; com o avanço do processo, o setor privado (em especial, o setor bancário) seria estimulado a também financiar transações patrimoniais (cf. Binswanger \& Van Zyl, 1995, p. 255-7; Christiansen \& Van Den Brink, 1994, 154-156; Aiyar, Parker \& Van Zyl, 1995, 1995a).

Pode-se depreender que o MRAM, na sua versão original, exigiria uma ação de governo muito firme no sentido de: a) aprofundar o ajuste estrutural da economia nacional e, em especial, do setor agropecuário, de modo que o segmento dito "ineficiente" fosse exposto, sem cobertura estatal de qualquer tipo, aos efeitos da abertura comercial e da redução de subsídios e isenções fiscais; b) administrar a crise de endividamento do setor agropecuário comercial de modo seletivo, resistindo a pressões políticas para promover operações de 
"socorro" e renegociação de dívidas dos segmentos considerados "inviáveis", a fim de reestruturar a matriz de propriedade e de produção.

Nesta versão, estimava-se que o MRAM provocaria impactos estruturais - a meta de governo era redistribuir $30 \%$ das terras agrícolas em cinco anos (de 1994 a 1999), o que equivale a quase 30 milhões de hectares (Deininger, 2001, p. 93). Associado a outras ações, como a liberalização das relações de arrendamento (Van Zyl, 1995), o MRAM daria origem a uma "nova agricultura", condizente com a abertura radical do mercado agrícola doméstico. De acordo com essa proposição, o mercado de terras seria o principal mecanismo redistributivo (Van Schalkwyk \& Van Zyl, 1995, p. 205).

O BM monitorou a evolução do quadro sul-africano desde 1992, tendo influenciado no processo de liberalização econômica, na concepção da nova Constituição e na preparação do programa nacional de reforma agrária (Banco Mundial, 1997, p. 85; Tilley, 2002). Porém, esta versão do MRAM jamais se materializou na África do Sul, nem em qualquer outro país. Ao que tudo indica, a própria diretoria do BM não a endossou, uma vez que não foi efetuada nenhuma operação de empréstimo ao governo sul-africano nesse sentido.

Acompanhando os documentos do BM ao longo da segunda metade dos anos 90, é possível observar que aquela versão original foi dando lugar a outra, menos ortodoxa e mais circunscrita ao tema do alívio da pobreza e das "políticas de terra", no bojo das quais o MRAM seria apenas mais uma opção, e não a ação principal (Burki \& Perry, 1997, p. 97; Deininger \& Binswanger, 1998, 1999; Deininger, 1998, 2001; Banco Mundial, 2001, 2001a, 2002, 2003). Explicar o porquê do abandono da proposta original em favor de um enfoque mais pragmático e restrito escapa aos limites deste trabalho, mas, sem dúvida, qualquer interpretação deve se remeter aos problemas que a implementação dos programas orientados pelo MRAM vinha enfrentando na Colômbia e na África do Sul desde 1994 e, a partir de 1997, no Brasil. 
Nessa segunda versão - cuja elaboração se baseia nas experiências de projetos-piloto então em curso -, os termos da discussão sobre o MRAM passam a ter a seguinte configuração: a) desaparece por completo o tema da "administração da crise de endividamento do setor comercial", apesar do mesmo não ser um fenômeno exclusivamente sul-africano, de tal maneira que o debate e, mais do que isso, a dinâmica efetiva dos programas orientados pelo MRAM, passam a se dar de maneira desvinculada da realidade dos setores patronais, "viáveis" ou não sob o ajuste; b) prossegue a menção recorrente ao tema da eliminação das "distorções políticas" ("nivelamento do campo de jogo") que afetam o funcionamento dos mercados de terra; c) o MRAM deixa de aparecer como o instrumento central de uma estratégia de mudança da agricultura nacional; d) conseqüentemente, desaparecem os possíveis impactos estruturais que a sua execução poderia provocar; e) ganha ênfase a associação do MRAM com o tema mais restrito do alívio da pobreza rural, de modo que os programas implementados passam a se inserir direta e explicitamente no rol de políticas compensatórias aos efeitos socialmente regressivos provocados pelas contra-reformas estruturais capitaneadas pelo Fundo Monetário Internacional e o Banco Mundial.

O que há de comum entre ambas as versões? Ao menos, quatro elementos principais: a) a centralidade da liberalização dos mercados de compra e venda e arrendamento como forma de distribuição de terras dos produtores menos eficientes para os mais eficientes; b) a crítica sistemática à reforma agrária "conduzida pelo Estado", considerada inviável e indesejável nos dias atuais; c) a equivalência do MRAM à reforma agrária redistributiva, como se fossem sinônimos; d) a ênfase na necessidade de avanço e aprofundamento das reformas estruturais e institucionais, de modo a consolidar novas condições macroeconômicas e prosseguir no ajuste das políticas setoriais. 


\section{Crítica ao modelo de reforma agrária de mercado}

3.1 O que está em jogo na crítica do BM à reforma agrária "conduzida pelo Estado"?

Não tem sido devidamente notado no debate corrente o seguinte: o que o BM denomina de modelo "tradicional" de reforma agrária não passa de uma caricatura, como tal inexistente no mundo real. Opera-se um raciocínio que sai da análise empírica e chega à idealização, porque constrói-se um "modelo" que concentra em si todas as características supostamente negativas das políticas de reforma agrária realizadas ao longo do século XX. A base do discurso do BM não é a análise de processos históricos de reforma agrária, mas sim a montagem de um "modelo" ao qual se atribui uma responsabilidade quase que genética pelo suposto fracasso das reformas agrárias realizadas em grande parte da América Latina, da África e da Ásia. Este ponto é importante para se entender a operação ideológica que dá substrato à construção do MRAM: a crítica ao modelo "tradicional" se faz de maneira abstrata, homogeneizadora e universalista, deslocada da análise empírica dos conflitos sociais que definiram a natureza, o grau, a extensão, o ritmo, a direção e mesmo o refluxo variável das políticas de reforma agrária, sempre heterogêneas entre si e ocorridas em sociedades diferentes umas das outras. ${ }^{3}$ Exemplo desse caráter caricatural é a repetição desse mesmo discurso para explicar o caso brasileiro: como considerar "esgotado" ou "falido" um "modelo" de reforma agrária que, a rigor, jamais foi levado adiante em escala substantiva? Não se trata, portanto, de uma referência de análise, mas sim de uma caricatura construída justamente por aqueles que pretendem disputar política e ideologicamente - eis o cerne da questão - qual deve ser o papel do Estado em sociedades marcadas por grave problema agrário na atual fase do capitalismo.

Parte considerável da crítica pró-mercado de terras não tem qualquer fundamento (Borras, 2004, p. 59-60). Por exemplo, dificilmente alguém poderia defender a idéia de que as políticas de reforma agrária foram "dirigidas pela oferta", isto é, não tiveram ou não têm - como motor, em maior ou menor grau, a "demanda" 
por terra provocada pela luta social do campesinato, mais ou menos articulada conforme o caso. Também fica difícil explicar o suposto "fracasso" das reformas agrárias pelo seu caráter coercitivo, uma vez que os processos considerados bem-sucedidos tiveram alto grau de discricionariedade estatal. Igualmente, é incorreto vincular o resultado das reformas agrárias a políticas desenvolvimentistas "orientadas para dentro", uma vez que as sociedades periféricas, sobretudo as latino-americanas, sempre estiveram vinculadas de modo subordinado à internacionalização do capital. Também seria equivocado associar automaticamente o Estado e o caráter centralizado da política de reforma agrária à corrupção e à ineficiência, como se o mercado e a natureza descentralizada de qualquer política pública fossem ontologicamente imunes a desvios de finalidade e má administração. Por fim, é discutível definir como "bem" ou "mal" sucedido um determinado processo de reforma agrária, pois trata-se, sobretudo, de uma questão de grau de redistribuição de poder e riqueza. E tal redistribuição não se esgota em si mesma, mas interage o tempo todo com processos econômicos e disputas políticas mais abrangentes.

Evidentemente, nem tudo na crítica pró-mercado de terras é desprezível, já que os programas baseados na desapropriação padeceram - e ainda padecem, nos poucos países onde estão sendo precariamente implementados, como no Brasil - de enormes deficiências, provocadas por uma série de razões, dentre as quais o veto permanente das classes dominantes a qualquer política de natureza redistributiva e o sucateamento do aparato público voltado para garantir as condições necessárias ao desenvolvimento econômico e social dos assentamentos rurais. Porém, o que deve ficar claro é que a crítica pró-mercado de terras não ocorre num vazio histórico, nem tampouco é desprovida de intencionalidade política e ideológica. O seu pressuposto básico é o de que, diante da configuração do capitalismo contemporâneo e da dinâmica e do legado das políticas de ajuste estrutural, não há mais sentido em falar de reforma agrária. Trata-se do pressuposto da falência e do anacronismo. O seu corolário fundamental é o de que o Estado não deve desempenhar uma função verdadeiramente redistributiva, nem promover políticas sociais 
universais que recoloquem no centro da agenda econômica - e não à margem, como objeto de políticas focalizadas, descolado da noção de direito social - a questão do trabalho e da justiça social.

\subsection{O MRAM é uma modalidade de reforma agrária redistributiva?}

A resposta é não, pois o MRAM tem como princípio a compra e venda voluntária de terra entre agentes privados mediada pelo Estado acrescida de uma parcela variável de subsídio para investimentos socioprodutivos. Já o que se convencionou chamar de reforma agrária redistributiva consiste em ação pública que, num curto espaço de tempo, redistribui ao campesinato pobre terras privadas monopolizadas por uma classe de grandes proprietários. Seu objetivo é democratizar a estrutura de propriedade da terra numa dada sociedade, o que pressupõe transformar as relações de poder econômico e político responsáveis pela concentração fundiária. Falar em reforma agrária como política redistributiva implica, sobretudo, defender a desapropriação de terras privadas que não cumprem a sua função social (El-Ghonemy, 2002, p. 1; Barraclough, 2001, p. 378-379). Para isso, é preciso fortalecer a capacidade de regulação do Estado sobre o território rural contra a sua apropriação pelo capital privado.

É importante entender as reformas redistributivas como uma questão de grau (Borras, 2004, p. 28-29 e 47). Assim, duas variáveis são fundamentais para demarcar a intensidade da redistribuição de terras: a compensação dos proprietários e o pagamento pelos beneficiários. No primeiro caso, a variação vai de zero (expropriação integral) até um patamar abaixo do parâmetro de mercado. No segundo caso, vai de zero até um patamar abaixo dos custos de aquisição. A diferença entre a indenização e os preços de mercado, no primeiro caso, e a diferença entre o pagamento dos beneficiários e os custos de aquisição, no segundo caso, definem o grau de redistribuição. O pagamento das indenizações em títulos públicos resgatáveis a longo prazo foi a maneira historicamente encontrada para assegurar que o processo pudesse ganhar escala, uma vez que 
o pagamento à vista exigiria mobilização de recursos de uma só vez numa magnitude impraticável para as finanças públicas de qualquer país.

Não há, portanto, qualquer semelhança entre o MRAM e reformas agrárias redistributivas. Transações mercantis nada têm a ver com redistribuição do estoque de riqueza (no caso, a terra rural) acumulado por uma classe ou frações de classe. Também em nada se assemelha à democratização de poder político. A natureza voluntária e mercantil do MRAM o distingue indelevelmente de qualquer política de reforma agrária redistributiva, somente viável se for compulsória, o que exige uma ampliação do poder desapropriatório do Estado frente à propriedade privada, e não a sua redução, como pressupõe o MRAM (Barraclough, 2001; Mondragón, 2003; ElGhonemy, 2002; Riedinger et al., 2000; Borras, 2004). Ora, se o MRAM se baseia na redução do poder desapropriatório do Estado, e este poder é o que permite realizar processos de reforma agrária, a conclusão inescapável é a de que o MRAM, quando privilegiado, nega a própria possibilidade de reforma agrária.

\subsection{Resultados do MRAM na África do Sul, Guatemala, Colômbia e Brasil}

As pesquisas realizadas sobre os casos colombiano, guatemalteco, sul-africano e brasileiro mostram que os resultados obtidos contradizem as diretrizes centrais do MRAM e as expectativas inicialmente atribuídas a ele pelos seus proponentes e operadores locais.

No caso colombiano, a execução do MRAM teve resultados bastante distintos daqueles que haviam sido previstos:

a) o programa não conseguiu atingir escala, uma vez que no período de 1995 a 2001 foram financiadas tão-somente 12.974 famílias, que adquiriram 180.211 ha, num universo cuja demanda por terra era estimada pelo INCORA, em 1989, em 262 mil famílias sem terra e 613 mil famílias com 
terra insuficiente (Mondragón, 2003; Balcázar et al., 2003, p. 311);

b) em todos os anos de execução, o número de famílias que solicitou acesso ao crédito foi muito maior do que o número aceito, assim como a demanda foi maior do que a oferta de terras (Mondragón, 2003);

c) o programa incidiu sobre um segmento bastante restrito do mercado de terras, composto por médios proprietários arruinados pela abertura comercial, e nunca latifundiários, dinâmica da qual resultou um conjunto de transações que passou por fora do circuito das terras de melhor localização e qualidade (Mondragón, 2003);

d) parte significativa dos beneficiários está inadimplente, revelando que, mesmo com a alta taxa de subsídio conferida à compra da terra (70\%), os beneficiários não conseguem pagar as prestações (Mondragón, 2003; Banco Mundial, 2003, p. 150);

e) os preços pagos pela terra foram arbitrados pelos proprietários, em função da fragilidade política dos agricultores (Fajardo, 2002, p. 15);

f) a implantação do programa levou à sobrevalorização do preço da terra, pelo menos nos dois primeiros anos, período melhor conhecido (Deininger, 1998, p. 6);

g) a produção agrícola ficou tão-somente no nível da subsistência das famílias (Borras, 2001, p. 12).

Os resultados do MRAM na Guatemala (Garoz \& Gauster, 2003; Tanaka \& Wittman, 2004) lembram os do caso anterior:

a) de 1996 a outubro de 2001, financiou-se a compra de 54.611 ha por apenas 9.874 famílias, a um total de US\$42.821.787, num universo cuja demanda por terra é estimada entre 316 mil hectares e 500 mil famílias; 
b) o que predomina é a oferta de terras privadas de má qualidade e má localização;

c) o processo de seleção dos beneficiários e de liberação do crédito é extremamente lento e burocratizado, variando, respectivamente, de 13 a 24 meses e meio entre 1998 e 2001;

d) há inúmeros casos de irregularidades e desvios de finalidade no processo de seleção dos beneficiários;

e) a grande maioria dos projetos produtivos não tem rentabilidade comercial, em razão de serviços inadequados de assistência técnica, da falta de mecanismos de comercialização, da má localização e qualidade das terras compradas, da insuficiência de recursos para investimento e da ausência de preços favoráveis para a produção;

f) é muito baixa a participação dos beneficiários, seja por falta de conhecimento sobre as regras do programa, seja pela assimetria de poder entre os agentes envolvidos, seja ainda pelo trâmite extremamente burocrático do programa.

No caso da África do Sul, os resultados foram relativamente semelhantes:

a) entre 1994 e 2002, foi redistribuído apenas $1 \%$ da terra monopolizada pela elite branca (Tilley, 2002, p. 1);

b) entre 1994 e 1999, o MRAM e o programa de restituição beneficiaram apenas 60 mil famílias, envolvendo em torno de 667.825 mil ha, o que representa $1,13 \%$ da meta prevista (Tilley, 2002, p. 27);

c) majoritariamente, os projetos produtivos não saíram do nível da precária subsistência (Deininger \& May, 2000, p. 2122); 
d) em inúmeros casos houve sobrevalorização do preço pago pelas terras (El-Ghonemy, 2001, p. 121; Tilley, 2002, p. 4$16)$;

e) predominantemente, foram transacionadas as piores terras (Tilley, 2002, p. 5);

f) os procedimentos foram altamente burocráticos, impossibilitando, na prática, qualquer tipo de "auto-seleção" dos beneficiários e qualquer enfoque "dirigido pela demanda" (Tilley, 2002, p. 29-31).

Já o caso do Brasil - levando-se em conta apenas a experiência do Cédula da Terra ${ }^{4}$ - é um pouco distinto, pois as metas do projeto foram cumpridas, financiando-se entre julho de 1997 e dezembro de 2002 a compra de imóveis rurais e investimentos complementares a 15.267 famílias, com um custo total de $\mathrm{R} \$ 182.829,901$. Porém, em relação aos seus congêneres da Colômbia, Guatemala e África do Sul, as diferenças param por aí. Alardeado como projeto bem sucedido pelo BM, o Cédula da Terra, na verdade, não obteve resultados tão animadores assim, pois:

a) a maioria dos imóveis adquiridos estavam abandonados ou subutilizados, em razão da seca e da crise da pecuária e das culturas tradicionais (Buainain et al., 1999, p. 31);

b) a adesão social ao projeto foi fortemente condicionada pela seca, pelo grave empobrecimento e absoluta falta de perspectivas de trabalho dos trabalhadores rurais e pelo direcionamento que agentes do Estado e políticos locais imprimiram a todo processo - priorizando os mais pobres -, de modo que o Cédula da Terra foi considerado por muitos como uma espécie de "tábua de salvação" imediata, visão potencializada pelo "sonho" da terra de trabalho e moradia alimentado por aquelas populações (Groppo et al., 1998; Buainain et al., 1999, p. 27; Buainain et al., 2003, p. 18; Sauer \& Victor, 2002, p. 34-35); 
c) metade das associações comunitárias foi criada exclusivamente para participar do projeto, revelando-se um procedimento meramente burocrático, sem qualquer acúmulo organizativo produzido por uma história de lutas comuns entre seus membros (Buainain et al., 1999, p. 223);

d) os recursos destinados a investimentos produtivos foram consumidos, em grande medida e na maioria dos casos, como custeio diário, esgotando-se antes mesmo de cobrir o pacote mínimo de investimentos (Buainain et al., 2003, p. 100-101 e 150);

e) sinal da total falta de transparência e prestação de contas, pouco se sabe sobre o pagamento das prestações derivadas da compra de imóveis rurais, pois os dados oferecidos pelo BM são insuficientes e pouco confiáveis, na medida em que versam apenas sobre 243 associações comunitárias, quando, no final de 2003, constavam 609 delas (Banco Mundial, 2003a, p. 16; Pereira, 2004, p. 192);

f) as projeções de geração de renda estão longe de ser consideradas positivas, ainda mais considerando-se que, na maioria das regiões, estão atreladas ao desempenho comercial de uma só cultura (Buainain et al., 2003, p. 157170).

Em todos os quatro casos (Colômbia, Guatemala, África do Sul e Brasil), os resultados empiricamente verificados contradizem os pressupostos do MRAM e as expectativas atribuídas à sua implementação, uma vez que:

a) os preços pagos pela terra não foram tão baratos como prematuramente havia sido declarado, apesar do pagamento à vista, e a má qualidade das terras adquiridas em parcela significativa dos casos só vem a ressaltar esse fato, de modo que é válido afirmar que os programas se constituíram num prêmio a proprietários que, por meio deles, venderam propriedades abandonadas ou falidas; 
b) em nenhum dos quatro países foi ofertada no mercado uma quantidade substancial de terras por parte dos grandes proprietários endividados, apesar das políticas de ajuste e da queda conjuntural do preço da terra;

c) diversas evidências sugerem que a execução dos programas provocou o aumento do preço da terra em muitas localidades, ainda que tal efeito não tenha sido homogêneo;

d) majoritariamente, os projetos produtivos são dominados pela agricultura de subsistência, e não por uma agricultura comercial de alta rentabilidade, como o MRAM prescreve;

e) a quantia concedida a fundo perdido revelou-se insuficiente para alavancar a produção agrícola, de sorte que os mutuários dos programas implementados permanecem dependentes de uma política pública substantiva de crédito rural;

f) não ocorreu o acesso massivo a mercados formais de crédito privado para financiar investimentos na produção agrícola;

g) não foram implementadas paralelamente ao MRAM nem a tributação progressiva, nem a titulação sistemática, como também não avançaram os processos de modernização dos sistemas de registro e cadastro de terras, nem as medidas para se baixar os custos de transação;

h) ocorreu enorme déficit de participação social em diversos (em alguns casos, em todos) componentes e fases dos programas implementados;

i) os beneficiários tiveram poder desigual na negociação com os proprietários de terra, fato que, por si só, demonstra que a formulação do MRAM não leva em conta as relações realmente existentes de exploração econômica, dominação política e prestígio social inscritas no monopólio da propriedade da terra em países altamente desiguais; 
j) ficou evidenciado que são os agentes do Estado que efetivamente protagonizam todo o processo de compra e venda de terras, e não "compradores e vendedores voluntários e racionais", como pressupõe o MRAM;

1) não ocorreu nas associações comunitárias nenhum processo de "auto-seleção" dos beneficiários, pois, de diferentes maneiras, houve influência ou tutela de forças externas, como agentes governamentais, proprietários, políticos locais, ONGs, etc.;

m) na prática, a elaboração de projetos produtivos viáveis não se deu antes da aquisição da terra, como estabelece o MRAM, de modo que não serviu como pré-condição para as transações imobiliárias;

n) quando existiu, a assistência técnica foi precária e irregular, dificultando sobremaneira o desempenho produtivo das famílias financiadas;

o) em lugar algum houve um efetivo "campo de jogo nivelado", isto é, uma eliminação substancial dos privilégios estatais conferidos a grandes proprietários de terra e produtores agrícolas;

p) não houve transparência na execução dos programas nem prestação de contas dos seus resultados à sociedade, o que realça ainda mais a total falta de controle social e participação efetiva das famílias.

Tais resultados demonstram empiricamente que é nula a validade conceitual do MRAM e de todo o constructo que procura fundamentá-lo. Os seus pressupostos básicos não se materializaram nos programas implementados, assim como as vantagens atribuídas ao MRAM não se concretizaram.

Direcionados para países marcados por grave problema agrário e fortes tensões sociais no campo, os programas orientados pelo MRAM mostraram até o momento que: 
a) não contribuem para democratizar a estrutura agrária, nem é esse o seu objetivo, pois foram criados para tão-somente aliviar de maneira seletiva os efeitos sociais negativos provocados pelas políticas de ajuste estrutural;

b) não têm condições de minimamente atender à demanda por terra existente, porque são desprovidos da capacidade de ganhar escala social devido ao pagamento em dinheiro a preços de mercado;

c) são caros, o que os condena a serem programas de pequena dimensão socioeconômica, completamente incapazes de atender à magnitude do problema agrário existente;

d) em nada se assemelham a programas de reforma agrária redistributiva, nem tampouco se aproximam de qualquer noção de justiça social.

Por outro lado, em termos político-ideológicos, a implementação do MRAM trouxe ganhos significativos para a sua base de sustentação, porque: a) competiu com os programas de reforma agrária existentes, precariamente executados; b) contribuiu para reforçar a ideologia dominante que procura legitimar a mercantilização dos direitos sociais; c) serviu para que governos contornassem em maior ou menor grau a pressão social pró-reforma agrária; d) reforçou a crítica da direita sobre a ineficiência e a inviabilidade da reforma agrária na atualidade; e) reiterou o receituário difundido pelo $\mathrm{BM}$ e $\mathrm{o}$ FMI sobre a inviabilidade fiscal de políticas sociais de caráter estrutural, capazes de contribuir para reorientar a economia em direção a um novo padrão de desenvolvimento, pautado por políticas de caráter redistributivo.

\section{Desdobramentos recentes}

Em que pesem os ganhos de natureza político-ideológica, os programas orientados pelo MRAM perderam força em nível internacional, em razão das suas próprias contradições e 
inconsistências internas, do arranjo institucional montado para gerilos, da sua incapacidade de resolver os problemas reais do campesinato e/ou da oposição dos movimentos sociais. Nos casos da África do Sul, Guatemala e Colômbia, tais programas experimentaram retrocesso, paralisação ou redefinição, ficando muito abaixo das expectativas inicialmente projetadas pelo BM.

Recentemente, o próprio BM (2001, p. 97-98) admitiu que as expectativas atribuídas ao MRAM não se materializaram. Obviamente, isso não suscita nada que pudesse se assemelhar a uma autocrítica sobre a aplicação do modelo. Na verdade, o debate no interior do BM volta-se exclusivamente para a criação de mecanismos de alívio da pobreza rural mais baratos que o MRAM. Em termos de "recomendação de políticas", trata-se, mais uma vez, de reiterar o imperativo do ajuste fiscal e reproduzir uma concepção focalizada e minimalista de política social. A lógica desse pensamento é manter a separação entre a agenda política em favor do trabalho e da justiça social e o núcleo diretivo da política econômica.

Porém, ao contrário do que vem ocorrendo nos demais países, os programas orientados pelo MRAM não se enfraqueceram politicamente no Brasil. O apoio da CONTAG e, secundariamente, da FETRAF-Brasil a tais programas permitiu a sua continuidade pelo governo Lula (Pereira, 2004), projetando o caso brasileiro como a principal - e única - experiência em curso em nível internacional com aporte de recursos significativo do BM e potencial de expansão. ${ }^{5}$ Tal continuidade fragilizou a posição política das organizações sociais contrárias às ações do BM no Brasil e no exterior, especialmente as de caráter rural.

De todo modo, não há como negar que o conflito social em torno da apropriação e uso da terra permanece significativo em todos os países onde tais programas foram implementados. O caso brasileiro, exaltado como o mais bem-sucedido pelo BM, é emblemático a esse respeito: o legado do Cédula da Terra e dos demais programas foi incapaz de conter o crescimento exponencial de ocupações e acampamentos de trabalhadores rurais sem terra ao 
longo do biênio 2003-4, revelando a magnitude da demanda por terra reprimida durante o segundo governo Cardoso (1999-2002).

Mesmo com a manutenção dos programas orientados pelo MRAM no Brasil, existem críticas em nível internacional a respeito da sua replicabilidade em outros países. À direita, encontram-se posições que, sem negar a sua experimentação, ressaltam os custos elevados desse tipo de programa. Esse espectro abarca desde setores do próprio $\mathrm{BM}$ até especialistas renomados, e normalmente está centrado na defesa de enfoques alternativos, predominantemente o arrendamento de terras (Banco Mundial, 2003b, 2002, 2001; De Janvry \& Sadoulet, 2000; De Janvry, Sadoulet \& Macours, 2000; Molina, 2001; Jaramillo, 1998). À esquerda, localizam-se as forças políticas que exigem a sua suspensão imediata, como a Via Campesina, a FIAN e um enorme conjunto de entidades signatárias do recente Fórum Mundial sobre a Reforma Agrária (CGRA, 2004; FIAN \& Via Campesina, 2002; FIAN et al., 2001; FMRA, 2004).

Possivelmente, esse conjunto variado de críticas e objeções explique por que o atual relatório sobre políticas de terra do BM (2003, p. 154) secundarize o MRAM, apresentando uma posição mais matizada sobre o tema. Cabem duas observações a esse respeito.

A primeira é que, apesar do tom mais conciliador, o BM prossegue com o mesmo deslizamento semântico que caracteriza toda a construção do MRAM. A intencionalidade dessa operação é clara: rebaixar politicamente a própria definição de reforma agrária, alargando-a de tal maneira que até mesmo programas de financiamento de compra e venda de terras entre agentes privados ou seja, o MRAM - passam a ser considerados "instrumentos de reforma agrária". Trata-se de uma tentativa de redefinição do sentido e do significado da reforma agrária no mundo contemporâneo, em disputa direta com a visão de mundo e a plataforma política dos movimentos sociais, especialmente daqueles aglutinados na Via Campesina.

A segunda observação é que, mesmo apresentando uma visão mais flexível em relação à questão específica do MRAM, o BM 
(2003, p. XLVI) afirma também que qualquer programa de reforma agrária deve, antes de ser iniciado, esgotar todas as alternativas menos controvertidas politicamente e de custo menor. E quais são as alternativas sugeridas? Justamente o conjunto de políticas de terra do próprio $\mathrm{BM}^{6}$ centrado na mercantilização máxima da terra, na crítica a políticas sociais de caráter universal e no ataque à função redistributiva do Estado (cf. Pereira, 2004). Tanto isso é verdade que, para o BM, independentemente da discussão sobre qual "modelo" de reforma agrária, deve-se criar condições para a ativação e dinamização dos mercados fundiários como meio preferencial de acesso à terra pelo campesinato pobre (Van Den Brink, 2003, p. 23).

Portanto, apesar de apresentar indicações sobre a secundarização do MRAM como política de alívio da pobreza rural um recuo em relação à sua euforia inicial -, o BM ainda não o descarta por completo.

Possivelmente, o desdobramento da experiência brasileira jogará papel central - talvez decisivo - no futuro do MRAM como proposta aplicável aos países do Sul. Ainda é cedo para afirmar se os programas orientados pelo MRAM vão ser plenamente executados no Brasil - dando origem a um novo arranjo de políticas agrárias de caráter misto -, ou vão redundar em fracasso e desmoralização para o BM e os governos que os implementarem. De todo modo, com a expansão do "agronegócio", sobretudo após 1999 (Delgado, 2004), não mais se observa aquela condição tida como fundamental para a implementação do MRAM: a redução significativa do preço da terra.

\section{Notas}

1 Cf. Binswanger (1995), Binswanger \& Elgin (1989), Burki \& Perry (1997), Deininger (2001, 2001a); Deininger \& Binswanger (1999, 1998), Deininger, Binswanger \& Feder (2001), Deininger \& Feder (2002).

2 Cf. Aiyar, Parker \& Van Zyl (1995, 1995a), Binswanger (1995), Burki \& Perry (1997), Deininger (2001, 2001a, 2000); Deininger \& Binswanger (1999, 1998), Binswanger \& van Zyl (1995), Christiansen (1995), Christiansen \& van den Brink (1994), Van Den Brink (2003), Van Schalkwyk 
\& Van Zyl (1995), Van Zyl, Kirsten \& Binswanger (1995) e Banco Mundial (s/d, 2003b).

3 Cf. Barraclough (2001), Thiesenhusen (1995), Wolf (1984), Huizer (2001), El-Ghonemy (2001), Borras (2004), Kay (1999, 1999a, 1998 e 1995) e Fox (1992).

4 A rigor, a experiência brasileira com os programas orientados pelo MRAM durante o governo Cardoso envolveu outros três programas além do Cédula da Terra: o projeto São José (conhecido como "Reforma Agrária Solidária"), o Banco da Terra e o Crédito Fundiário de Combate à Pobreza Rural. Por falta de espaço, dar-se-á ênfase apenas ao caso citado. Uma análise de todos os programas está em Pereira (2004).

5 Em 2001, ainda no governo Cardoso, foi oficializado um empréstimo com o BM no valor de EUR 436,4 milhões para a criação do Crédito Fundiário de Combate à Pobreza Rural (CFCP), cuja meta é financiar a compra de terras por 50 mil famílias em 14 estados (BA, SE, AL, PE, PB, RN, CE, PI, MA, MG, ES, PR, SC e RS) em três anos, sendo 40 mil no Nordeste, 5 mil no Sudeste e mais 5 mil no Sul. A meta global é financiar 250 mil famílias em 10 anos, num projeto que teria ainda mais duas fases, o que alcançaria o custo total de US $\$ 2$ bilhões, sendo U\$ 1 bilhão via empréstimo do BM. As próximas duas fases já foram aprovadas pela diretoria do BM e sua concretização dependerá do interesse do governo brasileiro, da execução do projeto e do formato dos acordos futuros com o BM. A previsão inicial era que a primeira fase do projeto teria início em fevereiro de 2001 e conclusão em setembro de 2004. Porém, o CFCP teve início apenas em abril de 2002, último ano do governo Cardoso. O governo Lula solicitou e o BM aprovou uma prorrogação do acordo de empréstimo até agosto de 2006. Como a desvalorização do Real em 1999 não correspondeu a um aumento de custos na mesma proporção, estima-se que o governo federal cancelará cerca de EUR 45 milhões do acordo de empréstimo da primeira fase, mas poderá, ainda sim, financiar cerca de 60 mil famílias, dez mil a mais do que a meta inicial estipulada.

6 A atual política agrária do BM tem como objetivo estimular o arrendamento de terras, a compra e venda de imóveis rurais, a titulação de posses informais, a privatização de fazendas estatais/coletivas, a reforma agrária de mercado, a construção de mecanismos de resolução de conflitos agrários, a montagem de um aparato administrativo de registro e cadastro de terras e, por fim, algum tipo de tributação da propriedade rural (preferencialmente, de forma municipalizada). 
Abstract: The political-ideological dispute between redistributive agrarian reform and the market land reform model of the World Bank (1994-2005)

The work analyses the political-ideological dispute between the market land reform model (MLRM) of the World Bank (WB) and redistributive agrarian reform. We argue that the core of this dispute lies in the fact that the MLRM was created to substitute the expropriative and redistributive role of the State. We show that in all countries where it was implemented (South Africa, Colombia, Guatemala and Brazil), the alleged advantages attributed to the MLRM over agrarian reform did not materialize.

Key-words: State; World Bank; agrarian reform; market land reform.

\section{Referências bibliográficas}

AIYAR, Swaminathan; PARKER, Andrew; VAN ZYL, Johan. Market-assisted land reform: a new solution to old problems. Washington D.C.: Agriculture and Natural Resources Departament, World Bank, 1995. (AGR Dissemination Notes, n. 4). Disponível em: <www.worldbank.org>.

Market-assisted land reform: helping solve a debt crisis. Washington D.C.: Agriculture and Natural Resources Departament, World Bank, 1995a. (AGR Dissemination Notes, n. 5). Disponível em: <www.worldbank.org>.

BALCÁZAR, Álvaro et al. Colombia: lecciones de la reforma agraria. In: TEJO, Pedro (Org.). Mercados de tierras agrícolas en América Latina y el Caribe: una realidad incompleta. Santiago do Chile: Nações Unidas, CEPAL, GTZ, 2003. v. 1.

BANCO MUNDIAL. Land policies for growth and poverty reduction. Washington D.C., 2003.

Implementation completion report $(C P L-41470)$. Report $\mathrm{n}^{\circ}$ 25973. 2003a.

Rural poverty alleviation in Brazil: toward an integrated strategy. Washington D.C., 2003b. 
BANCO MUNDIAL. Llegando a los pobres de las zonas rurales: estrategia de desarrollo rural para América Latina y el Caribe. [Washington D.C.], Departamento de Desarrollo Ambiental y Socialmente Sostenible, julho 2002.

. Relatório sobre o Desenvolvimento Mundial 2000-2001. Washington D.C., 2001.

. Rural development strategy and action plan for the Latin America and the Caribbean region. Washington D.C., 9 de julho de 2001a.

. Rural development: from vision to action - a sector strategy. Washington D.C., 1997.

. The theory behind market-assisted land reform. [s/d]. Disponível em: <www.worldbank.org>.

BARRACLOUGH, Sólon. A reforma agrária nos países em desenvolvimento: o papel do Estado e de outros agentes. In: TEÓFILO, Edson (Org.). A economia da reforma agrária: evidências internacionais. Brasília, 2001. (Estudos NEAD, n. 5).

BINSWANGER, Hans. The political implications of alternative models of land reform and compensation. In: VAN ZYL, Johan; KIRSTEN, Johann; BINSWANGER, Hans (Eds.). Policies, markets and mechanisms for agricultural land reform in South Africa. Draft Manuscript. 1995. (Publicado em 1996 por Oxford University Press).

BINSWANGER, Hans; ELGIN, Miranda. Quais são as perspectivas para a reforma agrária? Pesquisa e Planejamento Econômico, IPEA, v. 19, n. 1, abr. 1989.

BINSWANGER, Hans; VAN ZYL, Johan. Market assisted rural land reform: how will is work? In: VAN ZYL, Johan; KIRSTEN, Johann; BINSWANGER, Hans (Eds.). Policies, markets and mechanisms for agricultural land reform in South Africa. Draft manuscript. 1995. (Publicado em 1996 por Oxford University Press).

BORRAS, Saturnino. Rethinking redistributive land reform: struggles for land and power in the Philippines. The Hague, 2004. PhD Thesis, Institute of Social Studies.

. Questioning market-led agrarian reform. Working draft. The Hague, january, 2001. (Publicado no Journal of Agrarian Change, v. 3, p. 367-394, july, 2003). 
BUAINAIN, Antônio Márcio et al. Estudo de avaliação de impactos do programa Cédula da Terra, relatório final. Brasília: UNICAMP, NEAD, MDA, novembro, 2003.

. Relatório preliminar de avaliação do Projeto Cédula da Terra. Brasília: UNICAMP, NEAD, MEPF, junho 1999.

BUAINAIN, Antônio Márcio; SILVEIRA, José Maria da; TEÓFILO, Edson. O programa Cédula da Terra no contexto das novas políticas de reforma agrária, desenvolvimento e participação: uma discussão das transformações necessárias e possíveis. In: LEITE, Pedro Sisnando (Org.). Reforma agrária e desenvolvimento sustentável. Brasília: MDA, NEAD, 2000.

BURKI, Shahid Javed; PERRY, Guillermo. The long march. Washington D.C.: World Bank, 1997.

CGRA (CAMPANHA GLOBAL PELA REFORMAAGRÁRIA). Comentario sobre las políticas de tierra y desarrollo rural del Banco Mundial. 2004. Disponível em: <www.cadtm.org>.

CHRISTIANSEN, Robert. Overview of land reform issues. In: VAN ZYL, Johan; KIRSTEN, Johann; BINSWANGER, Hans (Eds.). Policies, markets and mechanisms for agricultural land reform in South Africa. Draft manuscript. 1995. (Publicado em 1996 por Oxford University Press).

CHRISTIANSEN, Robert; VAN DEN BRINK, Rogier. South african agriculture: structure, perfomance and options for the future. Washington D.C.: World Bank, Southern Africa Department, February, 1994.

DE JANVRY, Alain; SADOULET, Elisabeth. Access to land and land policy reforms. In: DE JANVRY, Alain; SADOULET, Elisabeth; GORDILLO, Gustavo; PLATEAU, Jean-Phillippe (Eds.). Access to land, rural poverty, and public action. London: Oxford University Press, 2001.

. Cómo transformar en un buen negocio la inversión en el campesinato pobre: nuevas perspectivas de desarrollo rural en América Latina. Texto apresentado na Conferencia sobre Desarrollo de la Economia Rural y Reducción de la Pobreza en América Latina y el Caribe, organizada pelo BID e patrocinada pelo governo da Dinamarca, Nova Orleáns, em março de 2000.

DE JANVRY, Alain; SADOULET, Elisabeth; MACOURS, Karen. Acesso a terra via mercados de arrendamento agrário na América Latina. 
Texto patrocinado pelo BID e apresentado no Seminário Regional sobre Mercado Agrário na América Latina e Caribe. Santiago, Chile, 30 de novembro a $1^{\circ}$ de dezembro de 2000. Disponível em: <www.nead.gov.br>.

DE JANVRY, Alain; SADOULET, Elisabeth; WOLFORD, Wendy. The changing role of the state in latin american land reforms. In: DE JANVRY, Alain; SADOULET, Elisabeth; GORDILLO, Gustavo; PLATEAU, Jean-Phillippe (Eds.). Access to land, rural poverty, and public action. London: Oxford University Press, 2001.

DEININGER, Klaus. Política y administración de tierras: lecciones recogidas y nuevos desafíos para la agenda de desarrollo del Banco Mundial. Washington D.C.: World Bank, 2001.

. Land markets and land reform. Texto apresentado na International Conference on Acess to Land: Innovative Agrarian Reforms for Sustainability and Poverty Reduction, Bonn, em março de 2001a.

. Making negotiated land reform work: initial experience from Colombia, Brazil, and South Africa. Washington D.C., 1998. Disponível em: 〈www.wordbank.org>.

DEININGER, Klaus; BINSWANGER, Hans. The evolution of the World Bank's land policy: principles, experience and future challenges. The World Bank Research Observer, Washington D.C., v. 14, n. 2, Aug. 1999.

. The evolution of the World Bank's land policy. Washington D.C., 1998.

DEININGER, Klaus; BINSWANGER, Hans; FEDER, Gershon. Poder, distorções, revolta e revolta nas relações de terras agrícolas. In: TEÓFILO, Edson (Org.). A economia da reforma agrária: evidências internacionais. Brasília, 2001. (Estudos NEAD, n. 5).

DEININGER, Klaus; FEDER, Gershon. Instituciones y política de tierras: mesajes fundamentales del Informe de la Investigación sobre política. Texto apresentado no Taller regional sobre asuntos de tierras en Latinoamérica y el Caribe, Pachuca, Hidalgo, em maio de 2002.

DEININGER, Klaus; MAY, Julian. Is there scope for growth with equity? The case of land reform in South Africa. Washington D.C., World Bank, 2000. (Working Paper, n. 2451). Disponível em: <www.wordbank.org>. 
DELGADO, Guilherme. Questão agrária brasileira no pós-guerra e sua configuração contemporânea. 2004. Versão preliminar (no prelo).

ECHEVERRÍA, Ruben. Opciones para fomentar el acceso a tierras. In: BANCO INTERAMERICANO DE DESENVOLVIMENTO. El acceso a la tierra en la agenda de desarrollo rural. Washington D.C., 2002.

. Un creciente interés en lograr mercados de tierras rurales más efectivos. In: BANCO INTERAMERICANO DE DESENVOLVIMENTO. Perspectivas sobre mercados de tierras rurales en América Latina. Washington, D.C.: Departamento de Desarrollo Sostenible, División de Medio Ambiente, 1998. (Informe Técnico, n. 124). Disponível em : <http://www.iadb.org/sds/doc/ 1093spa.pdf >.

EL-GHONEMY, M. Riad. Agrarian reform between government intervention and market mechanism. Texto apresentado na Conference on Agrarian Reform and Rural Development, organizada pelo Social Research Center of the American University, Cairo, 4 a 7 de março de 2002.

. The political economy of market-based land reform. In: GUIMIRE, Krishna B. (Ed.). Land reform and peasant livelihoods: the social dynamics of rural poverty and agrarian reforms in developing countries. London: ITDG Publishing, 2001.

FAJARDO, Darío. La tierra y el poder político: la reforma agraria y la reforma rural en Colombia. Land Reform, n. 1, 2002.

FIAN; VIA CAMPESINA. Carta abierta al Banco Mundial. Heidelberg,Tegucigalpa, 16 de abril de 2002.

FIAN et al. Declaración de Bonn sobre accesso a la tierra. Resolução final do seminário Acceso a la tierra: reformas agrarias inovadoras para la sustentabilidad y la reducción de la pobreza, 23 de março de 2001.

FMRA(FORO MUNDIAL SOBRE LA REFORMA AGRARIA). La reforma agraria y los recursos naturales: una exigencia de los pueblos. Declaración Final. Valencia, 8 de dezembro de 2004.

FOX, Jonathan. The politics of food in Mexico. Ithaca: Cornell University Press, 1992.

GAROZ, Byron; GAUSTER, Susana. Fontierras: el modelo de mercado y el acceso a la tierra en Guatemala - balance y perspectivas. In: BARROS, Flávia; SAUER, Sérgio; SCHWARTZMAN, Stephan (Orgs.) 
Os impactos negativos da política de reforma agrária de mercado do Banco Mundial. Brasília, Rede Brasil sobre Organizações Financeiras Multilaterais, 2003.

GORDILLO, Gustavo. Economía política de los derechos de propiedade de las instituciones agrarias en América Latina. Texto apresentado no Taller Regional sobre Asuntos de Tierras en Latinoamérica y el Caribe, Pachuca, Hidalgo, maio, 2002.

GROPPO, Paolo et al. Avaliação sintética do Projeto Cédula da Terra. Fortaleza: Convênio INCRA/FAO, maio, 1998.

HUIZER, Gerrit. Peasant mobilization for land reform: historical case studies and theoretical considerations. In: GUIMIRE, Krishna B. (Ed.). Land reform and peasant livelihoods: the social dynamics of rural poverty and agrarian reforms in developing countries. London: ITDG Publishing, 2001.

JARAMILLO, Carlos Felipe. El mercado rural de tierras en América Latina: hacia una nueva estrategia. In: BANCO INTERAMERICANO DE DESENVOLVIMENTO. Perspectivas sobre mercados de tierras rurales en América Latina. Washington, D.C.: Departamento de Desarrollo Sostenible, 1998. (Informe Técnico, n. 124).

KAY, Cristóbal. Mirando hacia atrás: el tiempo de las reformas agrarias. Envio, n. 208, julho, 1999.

. Mirando hacia atrás: el legado de las reformas agrarias. Envio, n. 209, agosto, 1999a.

. Latin America's agrarian reform: lights and shadows. Land Reform, n. 2, 1998.

. Desarrollo rural y cuestiones agrarias en la América Latina contemporánea. Agricultura y Sociedad, n. 75, p. 27-82, abr./jun. 1995.

MELMED-SANJAK, Jolyne; LAVADENZ, Isabel. La administración de tierras: un nuevo paradigma para un antigo problema. Texto apresentado no Taller Regional sobre Asuntos de Tierras en Latinoamérica y el Caribe, Pachuca, Hidalgo, maio, 2002.

MOLINA, Javier. Acceso a la tierra por medio del mercado: experiencias de bancos de tierras en Centroamérica. 2001. Disponível em: <www.pa.gob.mx>.

MONDRAGÓN, Hector. Colombia: o mercado de tierras o reforma agraria. In: BARROS, Flávia; SAUER, Sérgio; SCHWARTZMAN, Stephan 
(Orgs.). Os impactos negativos da política de reforma agrária de mercado do Banco Mundial. Brasília: Rede Brasil sobre Organizações Financeiras Multilaterais, 2003.

PEREIRA, João Márcio Mendes. O modelo de reforma agrária de mercado do Banco Mundial em questão: o debate internacional e o caso brasileiro: teoria, luta política e balanço de resultado. Rio de Janeiro, 2004. Dissertação (mestrado) - CPDA-UFRRJ. Disponível em: <www2.liphis.com> e <www.fmra.org>.

RIEDINGER, Jeffrey M. et al. Market-based land reform: an imperfect solution. Texto apresentado na International Conference on Agrarian Reform and Rural Development, Tagaytay, Filipinas, dezembro, 2000.

SAUER, Sérgio; VICTOR, Andréa Dias (Coords.). Estudo sobre a política do Banco Mundial para o setor agrário brasileiro com base no caso do Projeto Cédula da Terra. Brasília, Comissão Pastoral da Terra, outubro, 2002.

TANAKA, Laura Saldivar; WITTMAN, Hannah. Acordo de paz e Fundo de Terras na Guatemala. In: MARTINS, Mônica D. (Org.). O Banco Mundial e a terra: ofensiva e resistência na América Latina, Ásia e África. São Paulo: Boitempo, 2004.

TEÓFILO, Edson. Brasil: nuevos paradigmas de la reforma agraria. In: TEJO, Pedro (Org.). Mercados de tierras agrícolas en América Latina y el Caribe: una realidad incompleta. Santiago do Chile, Nações Unidas, CEPAL, GTZ, 2003. v. 1.

TEÓFILO, Edson et al. Políticas y instrumentos para promover el mercado de terras: enseñanzas de la experiencia brasileña. In: ECHEVERRÍA, Ruben (Org.). Desarrollo territorial rural en América Latina y el Caribe: manejo sostenible de recursos naturales, acceso a tierras y finanzas rurales. Cidade: Banco Interamericano de Desenvolvimento, 2003.

THIESENHUSEN, William. Broken promises: agrarian reform and the latin american campesino. Boulder: Westview Press, 1995.

TILLEY, Susan. An examination of market-assisted agrarian reform in South Africa. Commissioned by the International Union of Foodworkers (IUF), researched for the International Labour Resource and Information Group (ILRIG). 2002.

VAN DEN BRINK, Rogier. Land policy and land reform in Sub-Saharan Africa: consensus, confusion and controversy. Washington D.C., 2003. Disponível em: <www.worldbank.org>. 
VAN SCHALKWYK, Herman; VAN ZYL, Johan. The land market. In: VAN ZYL, Johan; KIRSTEN, Johan; BINSWANGER, Hans (Eds.). Policies, markets and mechanisms for agricultural land reform in South Africa. Draft Manuscript. 1995. (Publicado em 1996 por Oxford University Press).

VAN ZYL, Johan. A new vision for agriculture and management of the transition. In: VAN ZYL, Johan; KIRSTEN, Johan; BINSWANGER, Hans (Eds.). Policies, markets and mechanisms for agricultural land reform in South Africa. Draft manuscript. 1995. (Publicado em 1996 por Oxford University Press).

VAN ZYL, Johan; KIRSTEN, Johan; BINSWANGER, Hans. Introduction. In: VANZYL, Johan; KIRSTEN, Johan; BINSWANGER, Hans (Eds.). Policies, markets and mechanisms for agricultural land reform in South Africa. Draft manuscript. 1995. (Publicado em 1996 por Oxford University Press).

VAN ZYL, Johan; KIRSTEN, Johan; BINSWANGER, Hans (Eds.). Policies, markets and mechanisms for agricultural land reform in South Africa. Draft manuscript. 1995. (Publicado em 1996 por Oxford University Press).

WOLF, Eric. Guerras camponesas do século XX. São Paulo: Global, 1984. 